\title{
Nash Game Model for Optimizing Market Strategies, Configuration of Platform Products in a Vendor Managed Inventory (VMI) Supply Chain for a Product Family
}

\author{
Yugang Yu and George Q. Huang
}

\begin{tabular}{|l|l|}
\hline \multicolumn{2}{|l|}{ ERIM REPORT SERIES RESEARCHINMANAGMENT } \\
\hline ERIM Report Series reference number & ERS-2009-009-LIS \\
\hline Publication & March 2009 \\
\hline Number of pages & 29 \\
\hline Persistent paper URL & http://hdl.handle.net/1765/15029 \\
\hline Email address corresponding author & yyugang@ @rsm.nl \\
\hline Address & Erasmus Research Institute of Management (ERIM) \\
& RSM Erasmus University / Erasmus School of Economics \\
& Erasmus Universiteit Rotterdam \\
& P.O.Box 1738 \\
& 3000 DR Rotterdam, The Netherlands \\
& Phone: $\quad+31104081182$ \\
& Fax: $\quad+31104089640$ \\
& Email: info@erim.eur.nl \\
& Internet: $\quad$ www.erim.eur.nl \\
\hline
\end{tabular}

Bibliographic data and classifications of all the ERIM reports are also available on the ERIM website: www.erim.eur.nl 


\section{ERASMUS RESEARCH INSTITUTE OF MANAGEMENT}

\section{REPORT SERIES}

\section{RESEARCH IN MANAGEMENT}

\begin{tabular}{|l|l|}
\hline ABSTRACT AND KEYWORDS \\
\hline Abstract & $\begin{array}{l}\text { This paper discusses how a manufacturer and its retailers interact with each other to optimize } \\
\text { their product marketing strategies, platform product configuration and inventory policies in a VMI } \\
\text { (Vendor Managed Inventory) supply chain. The manufacturer procures raw materials from } \\
\text { multiple suppliers to produce a family of products sold to multiple retailers. Multiple types of } \\
\text { products are substitutable each other to end customers. The manufacturer makes its decision on } \\
\text { raw materials' procurement, platform product configuration, product replenishment policies to } \\
\text { retailers with VMI, price discount rate, and advertising investment to maximize its profit. Retailers } \\
\text { in turn consider the optimal local advertising and retail price to maximize their profits. This } \\
\text { problem is modeled as a dual simultaneous non-cooperative game (as a Nash game) model with } \\
\text { two sub-games. One is between the retailers serving in competing retail markets and the other is } \\
\text { between the manufacturer and the retailers. This paper combines analytical, iterative and GA } \\
\text { (genetic algorithm) methods to develop a game solution algorithm to find the Nash equilibrium. A } \\
\text { numerical example is conducted to test the proposed model and algorithm, and gain managerial } \\
\text { implications. }\end{array}$ \\
\hline supply chain management, vendor managed inventory, nash game model \\
\hline Availability & $\begin{array}{l}\text { The ERIM Report Series is distributed through the following platforms: } \\
\text { Academic Repository at Erasmus University (DEAR), DEAR ERIM Series Portal } \\
\text { Social Science Research Network (SSRN), SSRN ERIM Series Webpage } \\
\text { Research Papers in Economics (REPEC), REPEC ERIM Series Webpage }\end{array}$ \\
\hline Classifications & $\begin{array}{l}\text { The electronic versions of the papers in the ERIM report Series contain bibliographic metadata } \\
\text { by the following classification systems: } \\
\text { Library of Congress Classification, (LCC) LCC Webpage } \\
\text { Journal of Economic Literature, (JEL), JEL Webpage } \\
\text { ACM Computing Classification System CCS Webpage } \\
\text { Inspec Classification scheme (ICS), ICS Webpage }\end{array}$ \\
\hline
\end{tabular}




\title{
Nash game model for optimizing market strategies, configuration of platform products in a vendor managed inventory (VMI) supply chain for a product family
}

\author{
Yugang $\mathrm{Yu}^{*}$
}

Rotterdam School of Management, Erasmus University, the Netherlands

George Q. Huang

Department of Industrial and Manufacturing Systems Engineering, University of Hong Kong, P R China

\begin{abstract}
This paper discusses how a manufacturer and its retailers interact with each other to optimize their product marketing strategies, platform product configuration and inventory policies in a VMI (Vendor Managed Inventory) supply chain. The manufacturer procures raw materials from multiple suppliers to produce a family of products sold to multiple retailers. Multiple types of products are substitutable each other to end customers. The manufacturer makes its decision on raw materials' procurement, platform product configuration, product replenishment policies to retailers with VMI, price discount rate, and advertising investment to maximize its profit. Retailers in turn consider the optimal local advertising and retail price to maximize their profits. This problem is modeled as a dual simultaneous non-cooperative game (as a Nash game) model with two sub-games. One is between the retailers serving in competing retail markets and the other is between the manufacturer and the retailers. This paper combines analytical, iterative and GA (genetic algorithm) methods to develop a game solution algorithm to find the Nash equilibrium. A numerical example is conducted to test the proposed model and algorithm, and gain managerial implications.
\end{abstract}

Keywords: Supply chain management, Vendor Managed Inventory, Nash game model.

\section{INTRODUCTION}

VMI (Vendor Managed Inventory) is an inventory cooperation scheme in supply chains. Under a VMI system, the supplier decides on the appropriate inventory levels for each product of itself and its retailers, and the appropriate inventory policies to maintain these levels (Simchi-Livi et al., 2008). An early classical successful case for VMI is the partnership between Wal-Mart and Procter \& Gamble (P\&G). This partnership had dramatically improved P\&G's on-time deliveries and Wal-Mart's sales by $20-25 \%$ and in the inventory turnover by 30\% (Buzzell and Ortmeyer, 1995). Barilla, a pasta manufacturer, adopted VMI in 1988 , and became the largest pasta manufacturer in the world in 1990 , making $35 \%$ of the

\footnotetext{
*Corresponding author. Address: T10-38, RSM Erasmus University, 3062PA, Rotterdam, The Netherlands. Tel.:
} +31 10 4081387; fax: +31 10 4089014. Emails: yyugang@rsm.nl (Y. Yu) and gqhuang@hku.hk (G. Q. Huang) 
pasta sold in Italy and 22\% of pasta sold in Europe (Simchi-Livi et al., 2008). Dell and HP (Tyan and Wee, 2003) buy materials or modules from their suppliers (e.g., ink boxes, cables, plastics, circuit board for HP) to produce modules (e.g. subassemblies) and then products (e.g. notebooks or printers). With VMI, the products are distributed to retailers whose inventories are managed by the manufacturers to meet the requirements from end customers.

In VMI systems, except inventory management, some degree of autonomies is retained for individual enterprises to respond to changing environments. For example, enterprises enjoy the right of determining product prices and advertising investments in promoting products. Therefore, a question under concern is how each enterprise takes advantage of such autonomies in order to maximize its profit in a VMI system. However, it only receives little attention in literature except Yu et al. (2009a) and Yu et al.(2009b).

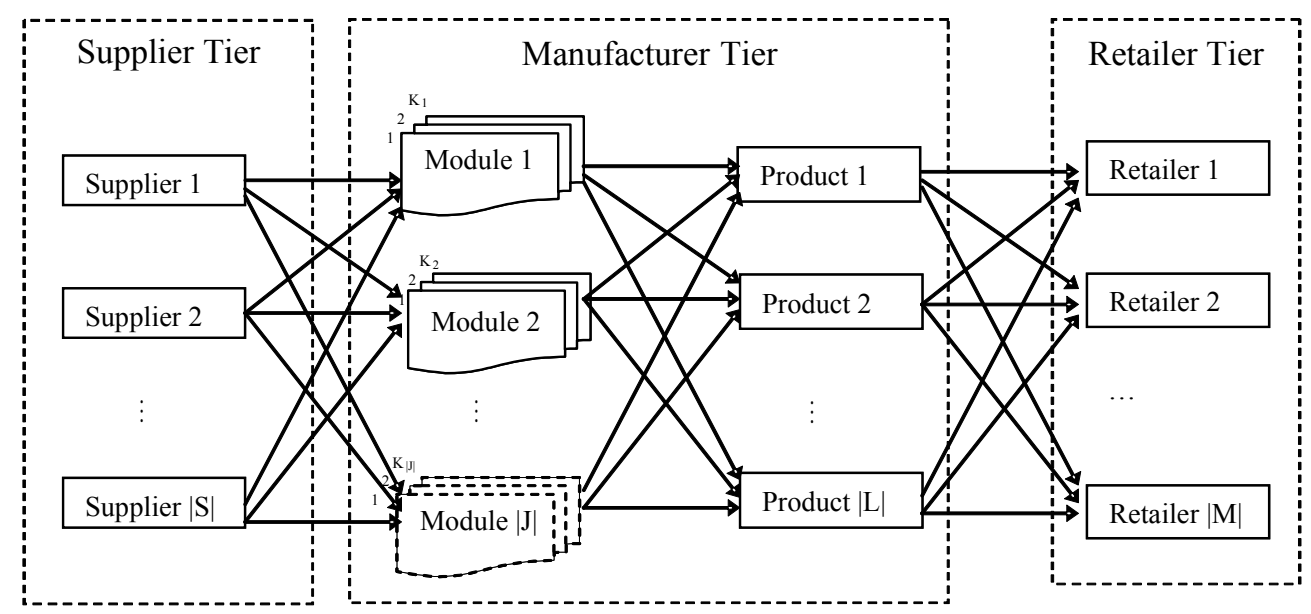

\section{Fig. 1 Supply chain overview}

This paper focuses on the above problem in a three-level supply chain (multiple suppliers, one manufacturer, and multiple retailers) with VMI partnership between one manufacturer (vendor) and multiple retailers (depicted in Fig. 1). In this supply chain, the manufacturer carries out core stages in product manufacturing process. From upstream suppliers, the manufacturer selects suppliers for purchasing raw materials or/and product components, and uses them to produce modules. Each of the modules has multiple alternatives (options) which can in turn be selected to assemble multiple substitutable products. The products are transported to different downstream retailers, and are finally sold in markets where the retailers and products compete with each other.

In the supply chain, retailers are able to determine their individual retail prices and advertising investments according to their own market environments so as to maximize their individual profits. The manufacturer is able to determine its advertising investment for its brand reputation, replenishment cycles for raw materials and finished products, platform 
product configuration and quantity discount to maximize its profit. According to VMI policy, the manufacturer normally can not know its retailers' decision processes but the decision results and their demand changes with time.

The approach we take in this research is to model the supply chain as a dual Nash game which is composed of two sub games. One is between the competing retailers in the retail sector and the other is between the manufacturer and individual retailers. The manufacturer and its retailers are of equal status, and they all do not the decision processes each other. All enterprises' decisions vary with the decision change of other enterprises and the equilibrium obtains when all enterprises are not willing to change their decisions, and this equilibrium is called as a Nash equilibrium. We propose an overall algorithm integrating analytic method, GA (genetic algorithm) and iterative method to solve this model.

The dual Nash game model and the proposed solution algorithm constitute a powerful decision support for solving the competitive supply chain configuration problem. Its use is demonstrated and tested through numerical examples. Several sensitivity analyses are conducted to assess what effects the competition between the products and retailers has on their business performance and what instruments the manufacturer and retailers have in order to adjust their business objectives. In the meanwhile, several sensitivity analyses are conducted to examine the mutual impacts of decision variables and parameters of different enterprises in the supply chain with fair competition.

The remainder of this paper is organized as follows. Section 2 briefly summarizes the relevant researches in the literature. Section 3 formulates the profit maximization problems of the retailers and the manufacturer respectively and mathematically defines the supply chain problems as a dual Nash game. Section 4 proposes brief solutions to the Nash game. Section 5 gives a numerical example and conducts some sensitive analyses. This paper should be considered as the prelude of our follow-up works as indicated in Section 6.

\section{LITERATURE REVIEW}

The research literature related to this paper can be divided into those on Supply chain configuration (SCC), those on Nash games in supply chain management. Although these areas are studied by many researchers, models simultaneously dealing with the above aspects are complex and sparse, especially those on games happening both among retailers, and between the manufacturer and retailers who produce or sale multiple substitutable products. 


\subsection{Supply chain configuration (SCC)}

Graves and Willems (2003) provide a focused review of the literature in this area so as to identify the relevant decisions that need to be considered in jointly optimizing production/distribution planning decision. In a vendor-managed inventory (VMI) system, Banerjee and Banerjee (1992) study how the vendor makes all replenishment decisions for its buyers to improve the joint inventory cost. Woo et al.(2001) and Zhang et al.(2007) extend their study to a three level supply chain where the procurement of one raw material is considered. However, only one product and raw material are involved in their models.

As reviewed by Yano and Dobson (1998), various models have been developed for extending and designing the product line instead of a single product to overcome the cost concerns of increased product variety. Kohli and Sukumar (1990) formulate a joint problem of designing a set of candidate products to maximize the manufacturer's profit margin. Raman and Chhajed (1995) formulate a complicated problem of choosing products and appropriate manufacturing process and product prices. Thonemann and Bradley (2002) investigate the impact of product variety on supply chain performance from several different perspectives. Their analyses show that product variety has significant effect on supply chain lead-time especially when setup times are significant. Huang et al.(2005) design effective supply chain systems that integrate platform product decisions, manufacturing process decisions and supply sourcing decisions using a mathematical model. They give answers how to generate the optimal configuration of the products, manufacturing processes and supply sources in order to form an effective and efficient supply chain in a simultaneous and integrated manner. However, what is the impact of the manufacturing decision of products on individual supply chain members, and vice versa? It is common but widely omitted in literature.

\subsection{Nash games in supply chain management,}

Cachon and Zipkin (1999) discuss Nash equilibrium in a non-cooperative cases in a supply chain there are one supplier and multiple retailers. They focus on how to use linear transfer payments to achieve the optimal profit of the system. Similar Nash game models can be found in Caldentey and Wein (2003 ). Dumrongsiri et al. (2008) investigate models by assuming that the consumers are sensitive to the price and service quality. They conclude that the marginal costs affect the Nash equilibrium result of the dual-channel supply chain. Nash game is also used by Cai et al.(2009) to address the effectiveness of price discount contracts in different scenarios and compared with some other games: supplier Stackelberg, retailer Stackelberg. They show that the price discount contracts outperform that of the non-contract 
scenarios. In VMI systems, Yu et al (2009a) study the pricing problem in a VMI system where the manufacturer needs to purchase raw materials to make products. However, it is unknown whether prices discount works in a supply chain where VMI is applied and multiple products compete each other. Moreover, they use Stackelberg game by assuming that the manufacturer knows retailers' information and decision processes. However, according to VMI policy, the manufacturer normally can not know its retailers' decision process but only the decision results and demand changes with time. Therefore Nash game would be more convincing in our case where the manufacturer and its retailers only respond to the others' results without knowing their decision processes.

Huang and Li (2001) study co-op advertisement in a supply chain context. They discuss the relationship between co-op advertising and the efficiency of manufacturer-retailer transactions by using Nash bargaining and Stackelberg game but inventory control is not considered. Most recently, Yue et al. (2006), based on Huang and Li (2001), study coordination of cooperative advertising in a two-level supply chain where the manufacturer offers price discount. Yu et al. (2009b) considers a VMI-type supply chain where both advertising and pricing are considered. In the supply chain, one manufacturer vendor) and multiple retailers are involved in producing, delivering and selling only one type of product. The manufacturer purchases multiple components or raw materials to make the product, produces the product and distributes it to its retailers. Each retailer buys the product from the manufacturer at the wholesale price, and then sells it to its consumer market at a retail price. However, they assume retailers' markets are independent of each other and only one product is considered.

In conclusion, our research differs from the previous papers reviewed above in several senses. We consider: (i) A three-echelon VMI supply chain in which multiple raw materials are purchased by the manufacturer to make multiple substitutable products sold by multiple retailers; (ii) a dual Nash games where competition simultaneously occurs both between a manufacturer and its retailers, and between multiple retailers; and between multiple substitutable products, and (iii) impact of suppliers selections and product production decisions on the profits of supply chain members. Due to this different setting, some innovative algorithms and new managerial insights are subsequently developed.

\section{DUAL NASH GAME MODEL}

This section mainly proposes a dual command Nash game model after we first define research context and notations. 


\subsection{Problem description and notations}

For the problem description, based on Fig. 1, we specify the research context as follows:

(1) There are a vendor (manufacturer) and multiple heterogeneous retailers in the VMI system. The vendor is a manufacturer who procures multiple raw materials and makes them into multiple modules. The modules can then be assembled into multiple products that are allocated into and sold by multiple retailers.

(2) VMI policy is adopted by the supply chain. The product demand and inventory information of the all retailers are available to the manufacturer. With this information, the manufacturer manages the inventories of the retailers and its own by determining product replenishment cycles. Because the inventories are managed by the manufacturer, the retailers pay inventory costs only according the amount of products bought, and the manufacturer pays all the rest.

(3) The retailers sell products in competing markets. Each retailer's revenue not only depends on its decision on retail prices and advertising investment, but is influenced by the same decisions from all the other retailers.

(4) The multiple products are substitutable. The products can have similar functions. The revenue of one product not only depends on its retail price and advertising investment, but also is influenced by pricing and advertising promotion from all the other products.

(5) The demand of one product type of a retailer is not only a function of the price and advertising investment of the product, but also a function of other products' prices and advertising investments by the same retailer, and the prices and advertising investments by all the other retailers on all the products, and the advertising investments of the manufacturer on all the products.

(6) The information exchanges among enterprises are limited; every enterprise (the manufacturer and the retailers) does not know their decision processes as enterprises realize the risk of revealing too much information. They can only react to the decision results of other enterprises.

(7) In our Nash game structure, a wholesale price is a negotiation result between the manufacturer and its retailers within a VMI ally. It is fixed; otherwise the manufacturer myopically prefers to raise the price as high as possible.

The notations used throughout the paper are summarised as follows:

Sets and indices:

$G$ : set of products, indexed by $g$, 
$J$ : set of modules, indexed by,

$K$ : set of module alternative options, indexed by $k$,

$L:$ set of materials, indexed by $l$,

$M$ : set of retailers, indexed by $m$,

$S:$ set of suppliers, indexed by $s$,

$G^{\prime}(g)$ : set of products whose production priority is lower than product $g$,

$G(j, k)$ : set of products in which the module alternative option $k$ in module $j$ is used,

$G(m)$ : set of products for retailer $m$,

$K(j)$ : set of module alternative options in module $j$, indexed by $k$,

$L(s)$ : set of raw materials purchasable from raw material supplier $s$,

$M(g)$ : set of retailers who sell product $g$,

$S(l)$ : set of suppliers of raw materials $l$,

Parameters and functions:

$D P_{m g}$ : demand volume of product $g$ for retailer $m$,

$e A_{m g y}$ : exponent of advertising investment $A_{y}$ on product $g$ in demand function $D P_{m g}$,

$e a_{m g x y}$ : exponent of advertising investment $a_{m g}$ in demand function $D P_{m g}$,

$e p_{m g x y}$ : exponent of retail price $p_{x y}$ in demand function $D P_{m g}$,

$F C A_{j k}$ : fixed cost for the manufacturer to develop module alternative $k$ in module $j$,

$F C M_{j}$ : fixed cost for the manufacturer to develop module $j$,

$F C P_{g}$ : fixed cost for the manufacturer to develop product $g$,

$H P_{g}$ : holding cost for the manufacturer to hold product $g$,

$H R M_{l}$ : holding cost per unit raw material $l$ per unit time,

$H R_{m g}$ : holding cost for retailer $m$ to hold one unit product $g$ per unit time,

$K_{m g}$ : a positive constant reflecting the market scale of product $g$ in retailer $m$,

$M M$ : an infinite positive number,

$M P_{g}$ : time needed for the manufacturer to product per unit of product $g$,

$O P_{m}$ : order cost for the manufacturer to retailer $m$ per time,

$O R_{m}:$ order cost for retailer $m$ per time,

$O R M_{s}$ : order cost per time for the manufacturer to procure raw materials from supplier $s$, $P C A_{j k}$ : module alternative option $k$ 's production cost in module $j$ for the manufacturer, $P C R_{s l}$ : procurement cost of material $l$ from supplier $s$, 
$P C P_{g}$ : production cost for product $g$,

$p w_{m g}$ : wholesale price of product $g$ for retailer $m$ after price discount,

$p w_{g}$ : wholesale price for product $g$ before price discount (the same to all retailers),

$T A$ : the upper bound of advertising investment for the manufacturer,

$T a_{m}:$ the upper bound of advertising investment for retailer $m$,

$T M P$ : total available man-hours for the manufacturer,

$T P_{m g}:$ transportation cost of product $g$ for retailer $m$,

$T R M_{s l}:$ transportation cost of raw material $l$ from supplier $s$,

$T V P$ : total inventory space available for the manufacturer,

$T V R_{m}:$ total inventory space available for retailer $m$,

$v_{m g x y}$ : coefficient of advertising investment $a_{x y}$ in demand function $D P_{m g}$,

$u_{m g y}$ : coefficient of advertising investment $A_{y}$ in demand function $D P_{m g}$,

$V_{g}:$ space occupied by a unit of product $g$,

$V R M_{l}:$ space occupied by a unit of raw material $l$,

$\delta_{g j k}$ : required number of module alternative option $k$ in module $j$ per product $g$,

$\sigma_{j k l}$ : required number of raw material $l$ for producing one unit of module alternative option $k$ in module $j$,

$\beta_{m g x y}$ : coefficient of retail price $p_{x y}$ in demand function $D P_{m g}$,

$w_{m}\left(1 \leq w_{m} \leq 2\right)$ : inventory space sharing factor of retailer $m$ 's warehouse $\left(w_{m}=2\right.$ for dedicated storage, and $w_{m}$ is normally close to 1 for random storage),

$w_{0}\left(1 \leq w_{0} \leq 2\right)$ : inventory space sharing factor of the manufacturer's warehouse $\left(w_{0}=2\right.$ for dedicated storage, and $w_{0}$ is close to 1 for random storage),

$N P_{0}:$ profit for the manufacturer,

$N P_{m}$ : profit for retailer $m$,

Decision variables for the manufacturer:

$A_{g}:$ advertising investment per unit time by manufacturer for its brand image (\$/time),

$D A_{j k}$ : demand volume of alternative option $k$ in module $j$ in product $g$,

$c_{m}:$ replenishment cycle for retailer $m$,

$\mathrm{crm}_{s}$ : replenishment cycle for the manufacturer procuring raw materials from supplier $s$,

$d r m_{s l}$ : demand rate of raw material $l$ from supplier $s$ (representing that raw material $l$ from 
supplier $s$ is not selected if $d r m_{s l}=0$ ),

$f a_{j k}$ : binary variable to indicate whether to develop (select) module alternative $k$ in module $j$, $f p m_{j}$ : binary variable to indicate whether to develop (select) module $j$,

$f p p_{g}$ : binary variable to indicate whether product $g$ is developed by the manufacturer or not,

$\rho_{g}$ : discount rate of product $g$ of the manufacturer to retailers (for the manufacturer),

Decision variables for retailers:

$a_{m g}:$ advertising investment per unit time for retailer $m(\$ /$ time $)$,

$p_{m g}:$ product retail price of product $g$ for retailer $m$.

\subsection{Framework of Dual Nash Game Model}

The dual Nash game depicted in Fig. 2 consists of two sub-games: a horizontal RR-Nash game and a vertical MR-Nash game.

Among the retailers, the decision process of retailer $m \in M$ is not disclosed to the others. However its decision results of $a_{m^{\prime}, g}, p_{m^{\prime}, g} m^{\prime} \in M, m^{\prime} \neq m \quad g \in G\left(m^{\prime}\right)$ of the other retailers are observable, can be taken used of, and then influence their profits. This forms a Nash game among all the retailers which is called RR-Nash game.

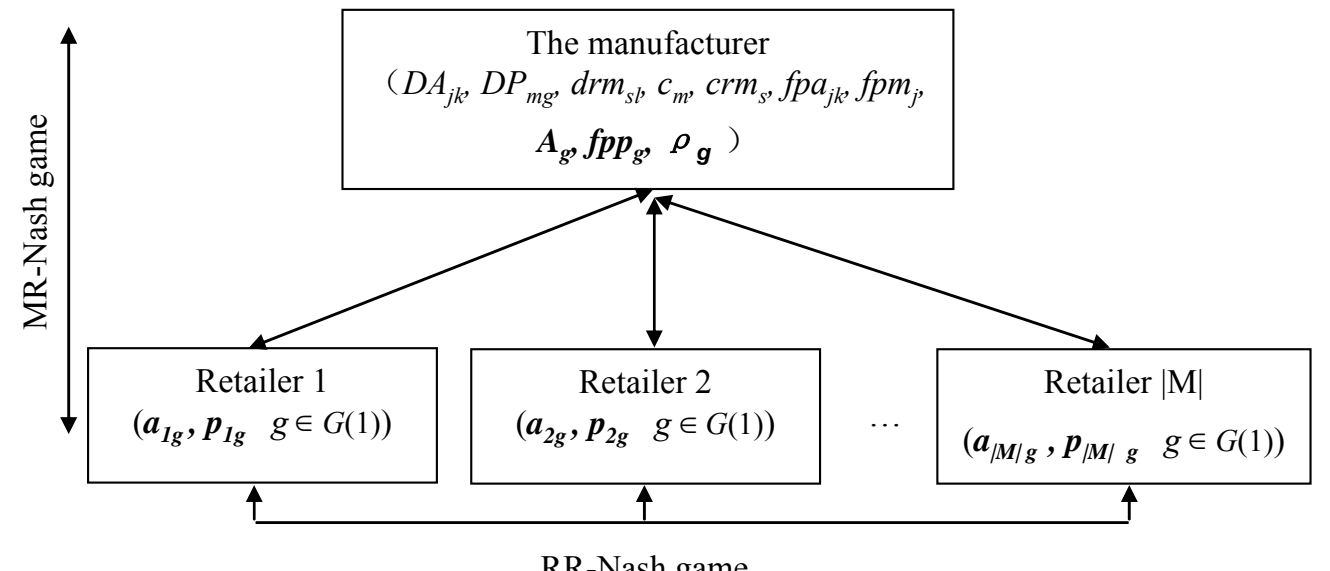

Note: [1] The variables in the brackets are decision variables; [2] The variables in bold are those whose values can affect other enterprises' profits.

\section{Fig. 2 The dual Nash games=(RR-Nash game) $+($ MR-Nash game)}

Similarly, between the manufacturer and retailer $m \in M$, the manufacturer's decision is influenced by the decision results of $a_{m g}, p_{m g} m \in M \quad g \in G(m)$ from its $|\mathrm{M}|$ retailers. The decision of retailer $m \in M$ on $a_{m g}, p_{m g} g \in G(m)$ is influenced by the manufacturer's decision on $A_{g}, f p p_{g}, \rho_{g} m \in M, g \in G(m)$. The interactions between them form a Nash game which is called MR-Nash game here. 
In the game system, every enterprise reacts to the decisions of the others. The whole system could reach such a stable situation (a Nash equilibrium) where no enterprises are willing to change their decisions as the change can not improve their own profits. That is to say, the profit of each enterprise is maximized which reaches the so-called overall Nash equilibrium; both RR-Nash game and MR-Nash game are in equilibrium.

\subsection{Formulation of RR-Nash game}

RR-Nash game is modeled in Fig. 3; retailer $m$ 's profit in Equation (5) is determined by its revenue $\sum_{g \in G(m)} D P_{m g} p_{m g}$ minus the total costs of buying products $\sum_{g \in G(m)} D P_{m g} p w_{m g}$, inventory cost $\sum_{g \in G(m)} \zeta_{m g} D P_{m g}$, and the advertising investment $\sum_{g \in G(m)} a_{m g}$. For the inventory cost, in accordance with the VMI policy mentioned in subsection 3.1, the inventory management are in the charge of the manufacturer, and a retailer only pays its inventory cost appropriate to its demand (without order costs and holding cost).

\section{HORIZONTAL GAME: RR-NASH:}

GAME PLAYERS: all the retailers in $M$

GIVEN (for all the retailers): Decision results from the manufacturer: $A_{g}, f p p_{g}$ and $\rho_{g}$.

GIVEN (for $\forall m \in M$ ):

The related fixed parameters and set parameters given in Subsection 3.1,

Variable results of the other competitive retailers: $p_{x g}$ and $a_{x g}, x \neq m, x \in M g \in G(x)$.

FIND (for $\forall m \in M$ ): $p_{m g}$ and $a_{m g} g \in G(m)$.

SATISFY (for $\forall m \in M$ ):

Wholesale price and demand functions:

$$
\begin{gathered}
D P_{m g}=K_{m g}+\sum_{y \in G} u_{m g y} A_{y}^{e A_{\text {mgy }}}+\sum_{x \in M, y \in G(x)}\left(\beta_{m g x y} p_{x y}^{e p_{\text {maxy }}}+v_{m g x y} a_{x y}^{e a_{m g r y}}\right) \quad g \in G(m) \\
p w_{m g}=p w_{g 0}-\rho_{g} D P_{m g} \quad g \in G(m) \\
\text { Resources constraints: } \quad w_{m} \sum_{g \in G(m)} c_{m} D P_{m g} V_{g} / 2 \leq T V R_{m} \quad \forall m \in M \\
\sum_{g \in G(m)} a_{m g} \leq T a_{m} .
\end{gathered}
$$

MAXIMIZE (for $\forall m \in M$ ):

$$
N P_{m}=\sum_{g \in G(m)} D P_{m g} p_{m g}-\sum_{g \in G(m)} D P_{m g} p w_{m g}-\sum_{g \in G(m)} \zeta_{m g} D P_{m g}-\sum_{g \in G(m)} a_{m g}
$$

\section{Fig. 3 RR-Nash game model}

With given decision results from the manufacturer on $A_{g}, c_{m}, f p p_{g}$ and $\rho_{g}$, retailer $m$ 's profits is not only determined by its decision on pricing $p_{m g}$ and advertising $a_{m g}$, but also 
heavily influenced by the decisions from the other retailers on their $p_{x g}$ and $a_{x g}$, $x \neq m, x \in M, g \in G(x)$ shown in Eq. (1) in which $\beta_{m g x y}, e a_{m g x y}, e A_{m g y}, e p_{m g x y}, u_{m g y}, v_{m g x y}$ are given in line with the properties: $\frac{\partial D P_{m g}}{\partial p_{m g}}<0, \frac{\partial D P_{m g}}{\partial p_{x y}}>0, \frac{\partial D P_{m g}}{\partial a_{m g}}>0, \frac{\partial D P_{m g}}{\partial a_{x y}}<0$, $x \neq m$ or $y \neq g, x \in M, y \in G(x)$.

These properties represent a common definition of substitutable products which goes back to Samuelson (1947). Moreover, the substitution among different products is defined.

Subsequently, retailer $m$ 's purchasing prices (wholesale prices) of the product from the manufacturer is influenced according to Eq. (2).

Besides, retailer $m$ 's resources may restraint its profit by its own warehousing capacity (see Eq. (3)) and available budget (see Eq. (4)).

In conclusion, in the RR-Nash game circumstances, it is important for individual enterprises to give their optimal response by determining $p_{m g}$ and $a_{m g}$ for maximizing their net profits under the competition among the different enterprises and different products.

\subsection{Formulation of the MR-Nash game}

The MR-Nash is depicted in Fig. 4 where the decisions between the manufacturer and a retailer $(\forall m \in M)$ are dependent each other while they are maximizing their individual profits.

Retailer $m$ 's demand for product $g, D P_{m g}$ (presented in Eq. (1)) is influenced by the manufacturer's advertising with $\frac{\partial D P_{m g}}{\partial A_{g}}>0$ and $\frac{\partial D P_{m g}}{\partial A_{y}}<0, y \neq g, y \in G$. Retailer $m$ 's purchasing price of product $g\left(p w_{m g}\right)$ is determined by the given decisions of the manufacturer on $p w_{g 0}$ and $\rho_{g}$ (see Eq. (2)).

For the manufacturer, its net profit is the revenue $\sum_{m \in M} \sum_{g \in G(m)} D P_{m g} p w_{m g}$ minus the total costs including the costs to manage inventories at the retailers' side $\left(\sum_{m \in M} \frac{1}{c_{m}} O R_{m}+\sum_{m \in M} \sum_{g \in G(m)} \frac{c_{m} D P_{m g} H R_{m g}}{2}\right.$ $\left.-\sum_{m \in M} \sum_{g \in G(m)} \zeta_{m g} D P_{m g}\right)$, the inventory costs at the manufacturer's side $\left(\sum_{m \in M} \frac{1}{c_{m}} O P_{m}\right.$ $\left.+\sum_{m \in M} \sum_{g \in G(m)} \frac{c_{m} D P_{m g} H P_{g}}{2}\right)+\left(\sum_{s \in S} \frac{1}{c r m} m_{s} O R M_{s}+\sum_{s \in S l \in L(s)} \frac{c r m_{s} d r m_{s l} H R M_{l}}{2}\right)$, the transport costs $\sum_{m \in M g \in G(m)} \sum_{m g} T P_{m g}$, the variable production or purchasing costs of the products, modules and raw materials $\sum_{m \in M} \sum_{g \in G(m)} D P_{m g} P C P_{g}+\sum_{j \in J} \sum_{k \in K(j)} D A_{j k} P C A_{j k}+\sum_{s \in S} \sum_{l \in L} d r m_{s l} P C R_{s l}$, the fix costs for producing or 


\section{VERTICAL GAME: MR-NASH:}

GAME PLAYERS: $\forall m \in M$, and the manufacturer

GIVEN (from all the other retailers):

Decision results from the other retailers $x \neq m, x \in M: p_{x g}$ and $a_{x g}, g \in G(x)$.

GIVEN (for the manufacturer):

The fixed parameters and set parameters given in Subsection 3.1,

Decision results for retailer $m: a_{m g}$ and $p_{m g}$.

FIND (for the manufacturer):

$A_{g}, c_{m}, \mathrm{crm}_{s}, d r m_{s l}, f p p_{g}, f p m_{j}, f p a_{j k}$, and $\rho_{g}$

SATISFY (for the manufacturer):

Wholesale price and demand functions: constraints (1) and (2) .

Logical constraints of BOM: $D A_{j k}=\sum_{g \in G(j, k)}\left(\delta_{g j k} \sum_{m \in M(g)} D P_{m g}\right) \quad \forall j \in J, k \in K(j)$

$$
\sum_{s \in S} d r m_{s l}=\sum_{j \in J} \sum_{k \in K(j)} \sigma_{j k l} D A_{j k} \quad \forall l \in L(j, k)
$$

Resource constraints:

$$
\begin{gathered}
w_{0}\left(\sum_{l \in L} \sum_{s \in S(l)} \frac{c r m_{s} d r m_{s l} V R M_{l}}{2}+\sum_{m \in M} \sum_{g \in G(m)} \frac{c_{m} D P_{m g} V_{g}}{2}\right) \leq T V P \\
w_{m} \sum_{g \in G(m)} c_{m} D P_{m g} V_{g} / 2 \leq T V R_{m} \quad \forall m \in M \\
\sum_{m \in M} \sum_{g \in G(m)} D P_{m g} M P_{g} \leq T M P \\
\sum_{g \in G} A_{g} \leq T A \\
A_{g} \leq A_{g}^{\max } g \in G
\end{gathered}
$$

Logical constraints of fixed costs: $\quad \sum_{m \in M(g)} D P_{m g} \leq M M \cdot f p p_{g} \quad \forall g \in G$

$$
\begin{gathered}
f p p_{g} \leq M M \cdot f p a_{j k} \quad \forall j \in J \quad k \in K(j) g \in G(j, k) \\
\sum_{k \in K(j)} f p a_{j k} \leq M M \cdot f p m_{j} \quad \forall j \in J
\end{gathered}
$$

Order of precedence:

$$
f p p_{g^{\prime}} \leq f p p_{g} \quad \forall g \in G, g^{\prime} \in G^{\prime}(g)
$$

MAXIMIZE (for the manufacturer):

$$
\begin{aligned}
& N P_{0}=\sum_{m \in M} \sum_{g \in G(m)} D P_{m g} p w_{m g}-\left(\sum_{m \in M} \frac{1}{c_{m}} O R_{m}+\sum_{m \in M} \sum_{g \in G(m)} \frac{c_{m} D P_{m g} H R_{m g}}{2}-\sum_{m \in M} \sum_{g \in G(m)} \zeta_{m g} D P_{m g}\right) \\
& -\left(\sum_{m \in M} \frac{1}{c_{m}} O P_{m}+\sum_{m \in M} \sum_{g \in G(m)} \frac{c_{m} D P_{m g} H P_{g}}{2}\right)-\left(\sum_{s \in S} \frac{1}{c r m_{s}} O R M_{s}+\sum_{s \in S} \sum_{l \in L(s)} \frac{c r m_{s} d r m_{s l} H R M_{l}}{2}\right) \\
& -\sum_{m \in M} \sum_{g \in G(m)} D P_{m g} T P_{m g}-\sum_{m \in M} \sum_{g \in G(m)} D P_{m g} P C P_{g}-\sum_{j \in J} \sum_{k \in K(j)} D A_{j k} P C A_{j k}-\sum_{s \in S} \sum_{l \in L} d r m_{s l} P C R_{s l} \\
& -\sum_{g \in G} f p p_{g} F C P_{g}-\sum_{j \in J} f p m_{j} F C M_{j}-\sum_{j \in J} \sum_{k \in K(j)} f p a_{j k} F C A_{j k}-\sum_{g \in G(m)} A_{g} .
\end{aligned}
$$

For retailer $m$, "GIVEN", "FIND", "SATISFY" and "MAXIMIZE" refer to Fig. 3.

Fig. 4 MR-Nash game model 
purchasing products, modules and raw materials $\sum_{g \in G} f p p_{g} F C P_{g}+\sum_{j \in J} f p m_{j} F C M_{j}+\sum_{j \in J} \sum_{k \in K(j)} f p a_{j k} F C A_{j k}$, and the advertising expenditure $\sum_{g \in G(m)} A_{g}$ for promoting the products. All these costs and the revenue are dependent on the pricing and advertising of individual retailers that influence the demands of products, $D P_{m g}$ (see Eq. (1)), and then the demands of the modules $D A_{j k}$, and of the raw materials $\sum_{s \in S} d r m_{s l}$.

Moreover, the manufacturer's profit is affected by its only constraints from product structures (see Eqs. (6) and (7)), available resources (see Eqs. (8)-(12)), fixed or setup costs (see Eqs. (13)-(15)) and the priority order for producing products (see Eq. (16)) if the resources are not abundant. We give further explanation of some constraints helping in understanding the model; Eq. (6) presents that to produce the units of $\sum_{m \in M(g)} D P_{m g}$ products, the requirement of alternative option $j$ in module $k$ is $D A_{j k}$. In Eq. (8), the value of $w_{0}$ depends on the various factors including storage policies, number of stored items types, etc. If the manufacturer uses the dedicated storage policy with which every item type occupies a predetermined and unsharable space, $w_{0}$ equals 2 and means that the require storage space is two times of the average storage level $\sum_{l \in L} \sum_{s \in S(l)} \frac{c r m_{s} d r m_{s l} V R M_{l}}{2}+\sum_{m \in M} \sum_{g \in G(m)} \frac{c_{m} D P_{m g} V_{g}}{2}$. If the random storage policy is applied, $w_{0}$ is close to 1 as multiple item types can share their storage spaces.

\section{SOLUTION ALgORITHM FOR NASH EqUILIBRIUM}

To obtain the equilibrium, we have to obtain: (i) the optimal response of individual enterprises to decision results of the other enterprises and (ii) the equilibrium conditions of the Nash Equilibrium. This section defines the response functions and the equilibrium conditions in subsection 4.1, discusses the calculation of the RR-Nash equilibrium in subsection 4.2. The manufacturer's optimal response function is developed in subsection 4.3, and the algorithm to find the global dual Nash game equilibrium is given in subsection 4.4.

\subsection{Introduction of calculating Nash equilibriums}

To simplify the explanation thereafter, we let $x_{0}$ denote the set of the decision variables $\left(d r m_{s l}, c_{m}, \mathrm{crm}_{s}, f p a_{j k}, f p m_{j}, f p p_{g}, A_{g}, \rho_{g}, s \in S, l \in L,, g \in G, k \in K(j), j \in J, m \in M\right)$ of the manufacturer, and $x_{m}$ represents the decision variables $\left(a_{m g}^{*}, p_{m g}^{*}, g \in G(m)\right)$ of retailer $m$, $m \in M$. For enterprise $m$, the set of decision variables of all the other enterprises is denoted as 
$x_{-m}=\left\{x_{0}, x_{1}, \ldots, x_{m-1}, x_{m+1}, \ldots, x_{|M|}\right\}, m \in M \cup\{0\}$. Therefore, the response function of enterprise $m$ can be defined as:

$$
x_{m}=r_{m}\left(x_{-m}\right),
$$

which means that the decision, $x_{m}$, of enterprise $m$ is a function, $r_{m}(\bullet)$, of the variable $x_{-m}$.

For realizing a Nash equilibrium, the enterprises (players) normally are in a dynamic reaction process with multiple interactive and iterative stages. At any given stage $k$, with the decision results $x_{-m}^{k}$ of the other enterprises, enterprise $m$ would make a response with:

$$
x_{m}^{k+1}=r_{m}\left(x_{-m}^{k}\right)
$$

to obtain its optimal decision $x_{m}^{k+1}$ for stage $k+1$.

With Eq.(19), the Nash game can be reached if it exists and satisfies (Liu, 1998):

$$
\sum_{m=0}^{|M|}\left\|x_{m}^{k+1}-r_{m}\left(x_{-m}^{k}\right)\right\|==0 .
$$

\subsection{Solving the Nash equilibrium of RR-Nash game}

Let $\lambda_{m}$ and $\gamma_{m}$ be the Lagrange multipliers for constraints (3) and (4) in Fig. 3. The Lagrange function $L_{m}$ of retailer $m$ 's model can then be expressed as follows:

$$
L_{m}=N P_{m}-\lambda_{m}\left(\sum_{g \in G(m)} w_{m} c_{m} D P_{m g} V_{g} / 2-T V R_{m}\right)+\gamma_{m}\left(\sum_{g \in G(m)} a_{m g}-T a_{m}\right)
$$

Then the optimal decision of $p_{m g}$ and $a_{m g}$ of retailer $m$ is determined by Kuhn-Tucker condition given in Eqs (22)-(25).

$$
\begin{gathered}
\frac{\partial N P_{m}}{\partial p_{m j}}+\frac{\lambda_{m} c_{m}}{2} \sum_{g \in G(m)} \frac{\partial D P_{m g} V_{g}}{\partial p_{m j}}=0, \quad j \in G(m), \\
\frac{\partial N P_{m}}{\partial a_{m j}}+\frac{\lambda_{m} c_{m}}{2} \sum_{g \in G(m)} \frac{\partial D P_{m g} V_{g}}{\partial a_{m j}}+\gamma_{m}=0, \quad j \in G(m), \\
\lambda_{m}\left(\frac{w_{m} \sum_{g \in G(m)} c_{m} D P_{m g} V_{g}}{2}-T V R_{m}\right)=0, \\
\gamma_{m}\left(\sum_{g \in G(m)} a_{m g}-T a_{m}\right)=0 .
\end{gathered}
$$

The number of variables $a_{m j}, p_{m j}, \gamma_{m}$ and $\lambda_{m} j \in G(m)$ is equal to that of equality equations. By solving the simultaneous Eqs. (22)-(25), we have

$$
x_{m}=r_{m}\left(x_{-m}\right) \quad m \in M .
$$

To repeat the decision process above for each retailer, we can obtain the optimal response function of every retailer. Therefore, for any given decision from the manufacturer, the RRNash game equilibrium can be obtained by solving the simultaneous equations (22)-(25) where $m=1, \ldots,|\mathrm{M}|$. 
Obviously, by setting $\left(x_{m}^{k}, x_{-m}^{k}\right)=\left(x_{m}, x_{-m}\right)$, for any given $x_{0}$, the solutions, $x_{-0}=\left(x_{1}, \ldots, x_{|M|}\right)$, of the simultaneous equations (22)-(25) with $m=1, \ldots,|\mathrm{M}|$ satisfy:

$$
\sum_{m=1}^{|M|}\left\|x_{m}^{k+1}-r_{m}\left(x_{-m}^{k}\right)\right\|==0 .
$$

According to Eq.(20), the RR-Nash equilibrium is then reached.

However, Eqs. (22)-(25) are nonlinear. The first step to resolve this kind of equations is to transform it into a series of linear simultaneous equations, and then to solve these linearized equations. Here, Newton-Raphson method (Press et al., 2007), which is convergence of $O\left(n^{2}\right)$ and $n$ is the number of variables, is used for transforming the simultaneous equation into linearized equations. Therefore, the RR-Nash game equilibrium is obtained.

\subsection{Optimizing the manufacturer's response}

To obtain the global Nash equilibrium, we should determine how the manufacturer gives its optimal reaction as a function of any given decisions from its retailers as a whole.

The manufacturer determines its optimal market and production decision variables under the MR-Nash model depicted in Fig. 4. Because several variables such as $f p p_{g} g \in G$ are not continuous variables, the Kuhn-Tucker condition cannot be applied here. Existing commercial software packages such as Lingo and CPLEX do not work effectively and cannot guarantee the optimal solution due to the possible existence of multiple local optimal solutions. Furthermore, it is difficult to integrate the solution of the RR game with that of MR game within such commercial software packages. Fortunately, these difficulties can be overcome by GA (genetic algorithm). We therefore adopt it as it is almost mature and widely used by other researchers (see Akyol and Bayhan, 2007; Liu, 1998; Solnon et al., 2008).The roulette wheel selection approach (Yang et al., 2007) and the elitist strategy(Onwubolu and Muting, 2001) are integrated to ensure that the best chromosomes can survive in the evolution.

We adopt the GA framework of Michalewicz (1996). With the algorithm we can find:

$$
x_{0}=r_{0}\left(x_{-0}\right) .
$$

There are some disadvantages to use the above GA directly. Generally, all the constraints are relaxed as penalty terms added to the objective function (the summation is called fitness function in GAs). The fitness function is used to evaluate the performance of GAs. The performance of a GA generally depends on the number of relaxed constraints, and the number of decision variables. The larger these numbers are, the worse performance (in terms of computation time to find a satisfactory solution) a GA has. Therefore, we simplify the 
manufacturer's decision model by eliminating some constraints and variables in order to improve the GA performance.

For equality constraints (6)-(7), they can be eliminated by substituting them into the objective function (17) or corresponding constraints. For example, Eq. (6) can be eliminated by replacing all $D A_{j k}$ in Eqs. (7) and (17) with $\sum_{g \in G(j, k)}\left(\delta_{g j k} \sum_{m \in M(g)} D P_{m g}\right)$. Meanwhile, the variable $D A_{j k}$ is eliminated. Moreover, the logical constraints (Eqs. (13)-(15)) for fixed costs can be replaced with "if...then..." sentences in programming codes.

For eliminating some variables, for example $c_{m}$, we can calculate $c_{m}^{*}=\sqrt{2 O P_{m} / \sum_{g \in G} D P_{m g} H P_{g}}$ (by solving $\partial N P_{0} / \partial c_{m}=0$ ) once the values $D P_{m g} g \in G(m)$ in the GA programming codes are obtained. With $c_{m}$ and $D P_{m g}$, we can obtain $w_{m} \sum_{g \in G(m)} c_{m} D P_{m g} V_{g} / 2$ (the right term of Eq. (9)), and then we check whether it is $=$ or $<T V R_{m}$. If " $<$ " holds, $c_{m}^{*}$ is the optimum and we do not need use "crossover" or "mutation" to generate a new $c_{m}^{*}$ for the given $D P_{m g}$. The similar simplification applies to $\mathrm{crm}_{s} s \in S$.

After the above simplifications, the fitness function, Fitness 0 for the manufacturer's decision becomes: Eq. (17) plus the discrepancies of Eqs. (8)-(12) and (16). The discrepancy of Eq. (9) is $f \sum_{m \in M}\left(w_{m} \sum_{g \in G(m)} c_{m} D P_{m g} V_{g} / 2-T V R_{m}\right)$ where $f<0$ is a penalty factor. The calculations of the other discrepancies are similar.

\subsection{The global Nash equilibrium of the dual Nash Game}

With the obtained response function of the manufacturer (see Eq. (28)) and the RR-Nash game equilibrium (determined by Eqs. (22)-(25) with $m=1, \ldots,|\mathrm{M}|$ ), the global equilibrium of the dual game can be obtained with the procedures given in Fig. 5 in which $k$ is the number of iterations for interactions among enterprises (see also Eq. (19)) and $n$ is the number of times to initialize $x_{0}^{k}$ and $x_{-0}^{k}$. In Fig. 5, there are five algorithmic steps:

Step 0: Randomly initialize the decision variables $x_{0}^{k}$ and $x_{-0}^{k}=\left(x_{1}^{k}, \ldots, x_{|M|}^{k}\right)$, with $k=0$ where $k$ is the iterative reaction stages between the enterprises. We set $n=1$ ( $n$ is used to count the number of .given initial values generated still now).

Step 1: Obtain the RR-Nash Equilibrium $x_{-0}$ based on the given $x_{0}^{k}$ by solving Equations Eqs. (22)-(25) with $m=1, \ldots,|\mathrm{M}|$. We replace $x_{-0}^{k}$ with $x_{-0}$ as $x_{-0}^{k+1}$. 
Step 2: Obtain the optimal value $x_{0}$ based on the given $x_{-0}^{k+1}$ with the GA as discussed in subsection 4.3. We replace $x_{0}^{k}$ with $x_{0}$ as $x_{0}^{k+1}$.

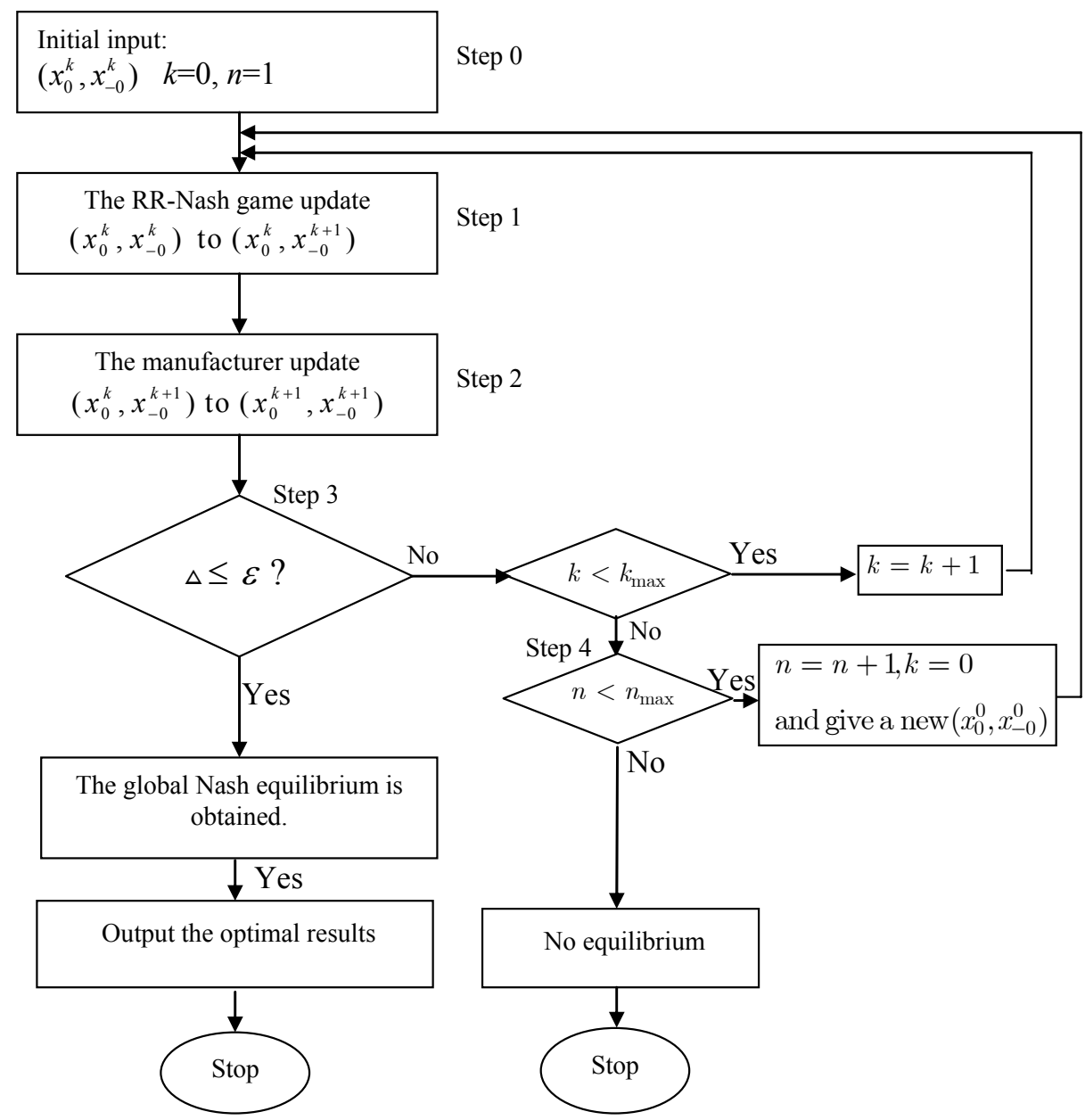

Fig. 5 Procedures for calculating the global Nash equilibrium

Step 3: With $\left(x_{0}^{k}, x_{-0}^{k}\right)$ and $\left(x_{0}^{k+1}, x_{-0}^{k+1}\right)$, we calculate the discrepancy: $\Delta=\sum_{m=0}^{|M|}\left\|x_{m}^{k+1}-r_{m}\left(x_{-m}^{k}\right)\right\|$.

(3.1) if $\Delta \leq \varepsilon$ ( $\varepsilon$ is a very small positive real number, e.g. 0.0001 ), we obtain the global Nash equilibrium according to Eq. (20) and output all the results; (3.2) if $\Delta>\varepsilon$ and $k<k_{\max }$, let $k=k+1$ and go to Step 1; (3.3) else we assume that, from the current initial variable, $\Delta$ can not converge to 0 and go to Step 4 .

Step4: We use the GA to generate another initial variable values. (4.1) If $n<n_{\max }$ ( $n_{\max }$ is a given maximum population size), we give a new initial value of $x_{0}^{k}$ and $x_{-0}^{k}$ and set $k=0$ for the iterative method in Steps 1-3 to search for a possible Nash equilibrium. Let $n=n+1$ and go to Step 1. In order to generate a good initial values $x_{0}^{k}$ and $x_{-0}^{k}$, we do not generate them randomly but with the GA; $\left(x_{0}^{k}, x_{-0}^{k}\right)$ with small $\triangle$ in Step 3 are remembered to generate an 
offspring (the new initial value $\left.\left(x_{0}^{0}, x_{-0}^{0}\right)\right)$. (4.2) else $n \geq n_{\max }$ we think the Nash equilibrium does not exist, and stop.

This flowchart of the proposed algorithm in Fig. 5 includes two main components, one being nested inside the other. The inner component is basically iterative and includes steps 1-3. They are mainly responsible for calculating the global Nash equilibrium with a given value of $\left(x_{0}^{0}, x_{-0}^{0}\right)$. If the equilibrium can not be achieved, a more time-consuming method of the outside component (Step 4) is used as a new round of search for the global Nash equilibrium.

\section{NUMERICAL EXAMPLE}

The example supply chain is sketched in Fig. 6. The details of the BOM (bills of materials) of the four product variants are shown in Fig. 7, from which the parameter values of $\delta_{g j k}$ and $\sigma_{j k l}$ are assigned. The values of the other parameters are given in Appendix A (see the online supplementary material of this paper).

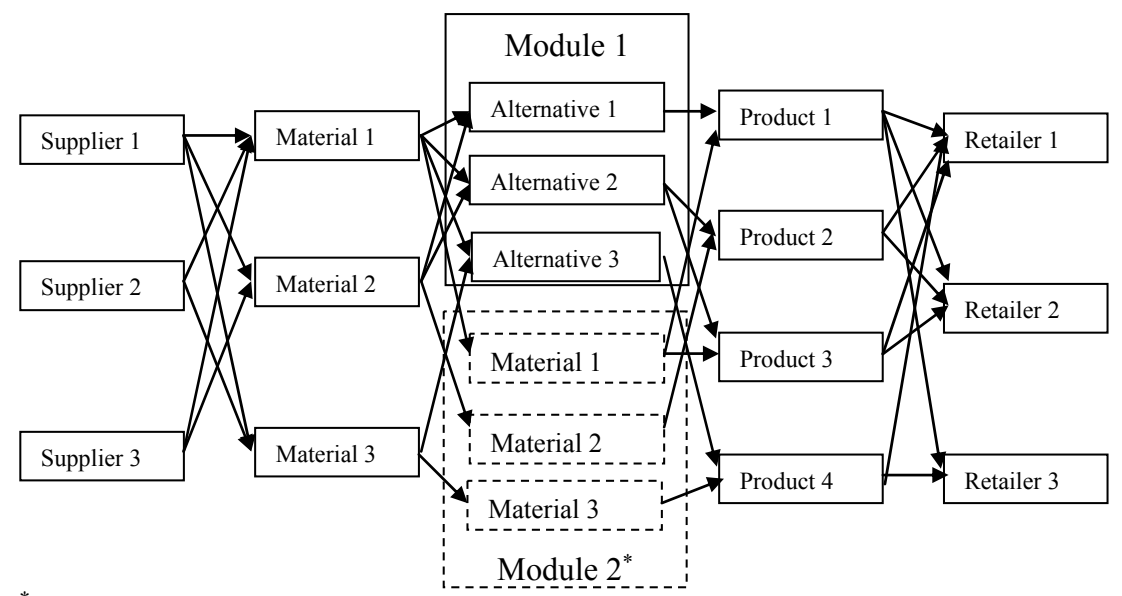

*Module 2 is dummy; each alternative option only consists of one unit of raw materials without production.

\section{Fig. 6. Settings for the example supply chain}

The computational parameters in the GA are population size $=120$, number of generations $=10000$, crossover probability $=0.7, \quad k_{\max }=n_{\max }=100$ and $\varepsilon=0.001 \%$. The algorithm programming is coded in Java 8.0.

Using the input parameters above (noted as scenario 1), we obtain the results at the global Nash game equilibrium shown in Table 1. 


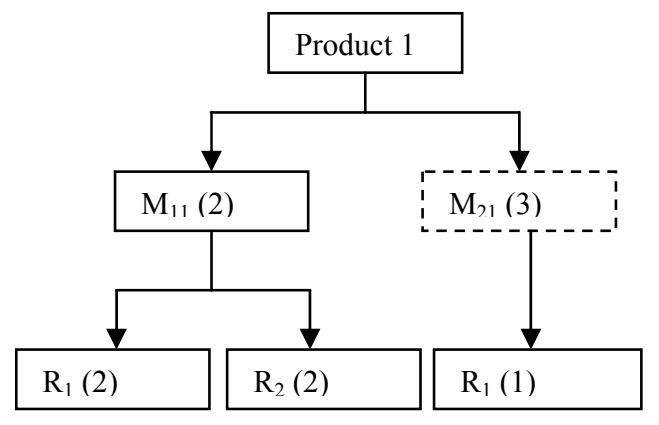

(a) Product 1 considering a dummy module

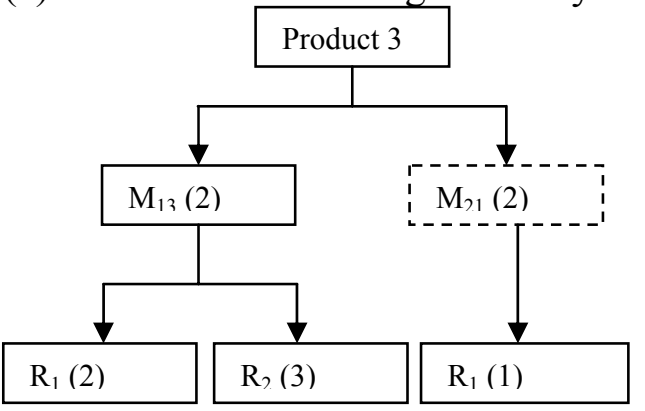

(c) Product 3 considering a dummy module

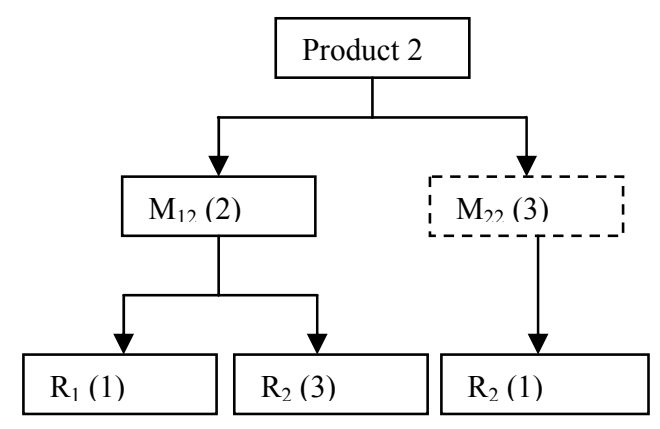

(b) Product 2 considering a dummy module

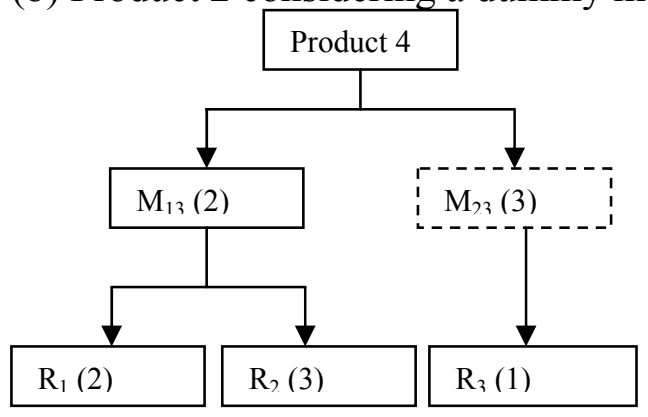

(d) Product 4 considering a dummy module Note: [1] $M_{j k}(n)$ represents that $n$ units of module alternative $k$ in module $j$ are required to produce one unit of their immediate upper level products; e.g. $\mathrm{M}_{21}$ (3) in (d) presenting $\delta_{421}=3$. [2] $R_{l}(n)$ represents that $n$ units of raw material $l$ are required to produce one unit of their immediate upper level modules. e.g. $R_{3}(1)$ in (d) representing $\sigma_{213}=1$.

\section{Fig. 7 BOMs of product variants}

To obtain more findings in different cases and the robustness of our algorithm, sensitivity analyses are conducted in the other 3 scenarios as shown in Table 1.

\section{Table 1 The other three scenarios}

\begin{tabular}{|c|c|c|c|}
\hline Scenario & Purpose & The changes from scenario 1 & $\begin{array}{l}\text { Selected } \\
\text { results }\end{array}$ \\
\hline 2 & $\begin{array}{l}\text { Give a better market } \\
\text { environments to retailer } \\
1\end{array}$ & $\begin{array}{l}\beta_{1111} \text { from }-19 \text { to }-18, \beta_{1212} \text { from }-25 \text { to }-24, \beta_{1313} \\
\text { from }-22 \text { to }-21, \beta_{1414} \text { from }-26 \text { to }-25, e A_{111} \text { from } \\
0.35 \text { to } 0.36, e A_{122} \text { from } 0.36 \text { to } 0.37, e A_{133} \text { from } \\
0.34 \text { to } 0.35, e A_{144} \text { from } 0.36 \text { to } 0.37 \text {. }\end{array}$ & Table 3 \\
\hline 3 & $\begin{array}{l}\text { Reduce the production } \\
\text { costs of product } 3\end{array}$ & $\begin{array}{l}F C P_{3} \text { from } 7000 \text { and } 2500, F C A_{1,3} \text { from } 4600 \text { to } \\
2000 \text {, and } T A \text { from } 14000 \text { to } 16000 \text {. }\end{array}$ & Table 4 \\
\hline 4 & $\begin{array}{l}\text { Make supplier 2's costs } \\
\text { relatively higher than } \\
\text { the other two suppliers. }\end{array}$ & $P C R_{13}$ from 1.4 to 1.1 , and $O R M_{1}$ from 60 to 45. & Table 5 \\
\hline
\end{tabular}

From our computational results, we obtain some interesting observations as follows:

1) Our algorithm can find the global Nash game equilibriums efficiently. All the computation times are between 20 minutes and 4 hours and most are within 1 hour on a computer with a configuration of CPU $2.4 \mathrm{G}$ and 528 RAM. This configuration is acceptable in practice for solving such problems. 
2) Retailers can be benefited from the improvements of other retailers' market circumstances (e.g. the demand of a product becomes less insensitive to the change of its retail price). The manufacturer can also be benefited. For example, in scenario 2, some parameters have been changed to make the demands of products 1,2 , and 4 less insensitive to the change of their market prices compared those in scenario 1. This change brings over a $20 \%$ increase in retailer 1's profit (compared the results in Table 3 and Table 2). Meanwhile, the profits of retailers $2 \& 3$, and the manufacturer increase by $4.69 \%, 5.24 \%$, and $7.71 \%$, respectively. This is because the improvement of retailer 1's market entices retailer 1 to raise the retail prices of products, and the manufacturer to invest more on advertising products. The other retailers are therefore benefited from the raised prices in retailer 1's markets and the added advertising investments by the manufacturer.

3) RR-Nash equilibrium can be changed significantly due to the change of the manufacturer's production costs. According to the results in Table 4 for scenario 3, the decrease in product 3's production cost makes the manufacturer decide to produce product 3. This brings the substantial changes of the retailers' profits; retailer 1's profit increases by $27.25 \%$ but retailer 3 's profit decrease marginally by $1.75 \%$ because product 3 in retailer 3's market is less demanding than in retailer 1's market.

4) The introduction of a new product can bring a loss to the other products. According to the results in Table 4(a), the profits of all the other products decrease in every retailer's market due to the substitutability between product 3 and the other products.

5) Lower prices offered by one supplier may not be enough to beat other suppliers. For example, although the price $\left(P C R_{32}=1\right.$ in Table 7$)$ of raw material 2 offered by supplier 3 is lower than that $\left(P C R_{12}=1.1\right.$ in Table 7$)$ offered by supplier 1, the manufacturer still prefer to purchase 2286 units of raw material 3 from supplier 1 (see Table 5(b) for scenario 4). This is because supplier 1 is already comparably bigger than supplier 2 , leading to less order cost per unit of raw material from supplier 1 than that from supplier 3 .

6) The supplier selection can be realized by our model. Table 5(b) shows that, with the reduction of the purchasing costs from the suppliers 1 and 3, the manufacturer decides not to purchase any raw materials from supplier 2 with $\mathrm{crm}_{2}=+\infty$. However, the re-selection of suppliers has little impact on the global Nash equilibrium, which can be observed from Table 2 and Table 5.

7) The discount rate is zero at our Nash equilibrium which differs from the discount rate normally larger than 0 in literature. This is because the different inventory partnerships are applied. In literature, the retailers' inventories are managed by themselves, and the 
manufacturer may therefore be benefited by putting more inventories to its retailers to reduce inventory holding cost and order cost. However, In the VMI system, all the inventories of the retailers are managed by the manufacturer who cannot be benefited from the transfer of the inventory locations. Moreover, the inventory cost at a central warehouse (the manufacturer's) is cheaper than in retailers'.

8) The optimal product portfolio can be determined by our model. It can be seen that it is not economical for the manufacturer to sell product 3. Similarly, module option 3 is not produced since it is only used by product 3 .

\section{Table 2: Results for scenario 1}

(a) The results for all retailers

\begin{tabular}{|l|l|l|l|l|l|l|l|}
\hline & Retailer & Product 1 & Product 2 & Product 3 & Product 4 & Total & $c_{m}^{*}\left(10^{-2}\right)$ \\
\hline Price & 1 & 67.88 & 61.02 & - & 55.72 & - & - \\
& 2 & 59.70 & 69.76 & - & - & - & - \\
Advertising & 3 & 70.69 & - & - & 63.57 & - & - \\
& 1 & 1049.85 & 2850.10 & - & 631.43 & - & - \\
& 2 & 357.29 & 1681.27 & - & - & - & - \\
Demand & 3 & 2509.19 & - & - & 1501.64 & - & - \\
& 1 & 507 & 538 & 0 & 306 & - & 17.21 \\
& 2 & 369 & 569 & 0 & 0 & - & 18.30 \\
& 3 & 574 & 0 & 0 & 456 & - & 14.03 \\
Profit & 1 & 14203 & 10722 & 0 & 3848 & 28773 & - \\
& 2 & 7877 & 17641 & 0 & 0 & 25518 & - \\
& 3 & 16612 & 0 & 0 & 8782 & 25394 & - \\
\hline
\end{tabular}

Note. "-" represents no existence of the data or non-valuable to give the data.

(b) The results for manufacturer

\begin{tabular}{|l|l|l|l|l|l|}
\hline & Product 1 & Product 2 & Product 3 & Product 4 & \multicolumn{1}{|c|}{ Total } \\
\hline Advertising & 3787 & 3562 & 0 & 6200 & - \\
Discount rate & 0 & 0 & 0 & 0 & - \\
Quantity & 1451 & 1107 & 0 & 762 & - \\
Profit & - & - & - & - & 38569 \\
Alternative 1 & 2902 & 0 & 0 & 0 & 2902 \\
Alternative 2 & 0 & 2214 & 0 & 1524 & 3738 \\
Alternative 3 & 0 & 0 & 0 & 0 & 0 \\
\hline
\end{tabular}

(c) Procurement plan for raw materials

\begin{tabular}{|l|l|l|l|l|}
\hline & Material 1 & Material 2 & Material 3 & $\operatorname{crm}_{s}^{*}\left(10^{-2}\right)$ \\
\hline Vendor 1 & 9532 & 0 & 0 & 16.73 \\
Vendor 2 & 842 & 0 & 2286 & 48.74 \\
Vendor 3 & 3520 & 20339 & 0 & 34.63 \\
Total & 13894 & 20339 & 2286 & - \\
\hline
\end{tabular}


Table 3: Selected results for scenario 2

(a) Profit structure for all retailers

\begin{tabular}{|l|l|l|l|l|l|}
\hline \multirow{2}{*}{ Retailer } & \multicolumn{3}{|l|}{ Profit for every product } & Total profit \\
\cline { 2 - 4 } 1 & 1 & 2 & 3 & 4 & \\
2 & 17482 & 13699 & 0 & 5373 & 36554 \\
3 & 8329 & 18389 & 0 & 0 & 26719 \\
\hline
\end{tabular}

(b) Market strategies and profits for the manufacturer

\begin{tabular}{|l|l|l|l|l|l|}
\hline & Product 1 & Product 2 & Product 3 & Product 4 & Total \\
\hline Quantities & 1512 & 1177 & 0 & 825 & \\
Advertisement fee & 4096 & 3987 & 0 & 6700 & \\
Discount rate & 0 & 0 & 0 & 0 & \\
Profit & - & - & - & - & 41353 \\
\hline
\end{tabular}

Table 4: Selected results for scenario 3

(a) Profit structure for all retailers

\begin{tabular}{|l|l|l|l|l|l|}
\hline \multirow{2}{*}{ Retailer } & \multicolumn{3}{l|}{ Profit for products } & Total profit \\
\cline { 2 - 5 } 1 & 1 & 2 & 3 & 4 & \\
2 & 13679 & 10117 & 8978 & 3452 & 36226 \\
3 & 7452 & 16591 & 3264 & 0 & 27306 \\
\hline
\end{tabular}

(b) Market strategies and profits for the manufacturer

\begin{tabular}{|l|l|l|l|l|l|}
\hline & Product 1 & Product 2 & Product 3 & Product 4 & Profit \\
\hline Quantities & 1399 & 1039 & 638 & 719 & 39269 \\
Advertisement fee & 3832 & 3436 & 1198 & 6199 & \\
Discount rate & 0 & 0 & 0 & 0 & \\
\hline
\end{tabular}

Table 5: Selected results for scenario 4

(a) Profit structure for all retailers

\begin{tabular}{|l|l|l|l|l|l|}
\hline \multirow{2}{*}{ Retailer } & \multicolumn{4}{l|}{ Profit for products } & Total profit \\
\cline { 2 - 5 } 1 & 1 & 2 & 3 & 4 & \\
2 & 14213 & 10723 & 0 & 3847 & 28782 \\
3 & 7882 & 17643 & 0 & 0 & 25525 \\
\hline
\end{tabular}

(b) Procurement plan for raw materials

\begin{tabular}{|l|l|l|l|l|}
\hline & Material 1 & Material 2 & Material 3 & $\mathrm{crm}_{s}^{*}\left(10^{-2}\right)$ \\
\hline Vendor 1 & 10487 & 0 & 2286 & 13.81 \\
Vendor 2 & 0 & 0 & 0 & $+\infty$ \\
Vendor 3 & 3409 & 20340 & 0 & 35.19 \\
Sum & $\mathbf{1 3 8 9 6}$ & $\mathbf{2 0 3 4 0}$ & $\mathbf{2 2 8 6}$ & - \\
\hline
\end{tabular}




\section{CONCLUSION AND FUTURE WORK}

This paper discusses a VMI supply chain where a manufacturer and multiple retailers interact with each other in order to minimize their own profits. Different from other research works in the literature, we conduct comprehensive investigation into how the horizontal RR Nash-games among retailers and vertical MR-Nash games between the manufacturer and retailers are impacted by multiple product substitutability, the market policies (advertising and pricing), product configuration, and supplier selections. We propose a dual Nash game model, consisting of RR-Nash game between retailers and MR-Nash game between the manufacturer and all retailers as a whole. We develop an algorithm to find the global Nash equilibrium efficiently. Numerical examples are analyzed to disclose some valuable insights below.

\subsection{Managerial implications}

The simultaneous non-cooperative game (a Nash Game in this paper) among retailers does not mean win-lost competition among them. Instead, this model demonstrates their mutual interests as a community. In our results, the better market environment of one retailer can lead to significant increases in all other enterprises' profits (see Table 2 and Table 3). When one retailer market environment is improved, the optimal retail prices and advertising investments will be enhanced. The increased optimal retail prices are beneficial to its substitutable products and the same product in other competing retailers. The profits of the other retailers can therefore increase as a consequence.

The changes of the manufacturer's production costs can have a significant impact on retailers' relative importance to the manufacturer. For example, the changes of production costs in scenario 2 make the introduction of a new product (product 3). This brings a significant increase in some retailers' profits (e.g. retailer 1), but has little impact on some other retailers' profits (e.g. retailer 3). Retailer 1 therefore changes from the smallest retailer in scenario 1 to the largest one in scenario 2.

Supplier selection is not only related to the procurement prices of raw materials, but also related to the procurement prices of other raw materials and fixed order costs from different suppliers. The manufacturer could purchase some units of a kind of raw material from a supplier who provides a higher price (than that offered by other suppliers) of the raw material (see Table 5(b) for raw material 3 from supplier 1). The reason is explained in Section 5.

Finally, it is not beneficial for the manufacturer to provide any price discount to retailers in this VMI system. This finding differs from that in the literature. In the literature, the retailers' inventories are managed by themselves and the manufacturer may therefore be 
benefited by pushing more inventories to its retailers to reduce inventory holding and order costs. However, In a VMI system, inventories of the retailers are managed by the manufacturer who cannot be benefited from the transfer of the inventory locations from its warehouse to its retailers'.

\subsection{Limitations and further research}

This study suffers from several limitations and further extensions are necessary in the future. Although suppliers, a manufacturer and retailers are considered, this supply chain can only be regarded as consisting of two echelons. This is because the suppliers are not treated as independent decision makers (game players). In the future study, some suppliers' decisions such as pricing and quantity discount can be considered.

The game model adopted in this paper is simultaneous and non-cooperative. The manufacturer and the retailers are considered of equal status. Other types of supply chain coordination schemes should be discussed in the future.

About the resource constraints, this paper only exemplifies some constraints for inventory space and man-hours. In fact, the manufacturer may confront other capacity constraints such as human resources; it could be valuable to consider these constraints in order to obtain more managerial insights.

\section{ACKNOWLEDGEMENTS}

Authors are grateful to the Grant for national outstanding young researchers (NWO VENI \#451-07-017) in the Netherlands, NSFC (\#70501027) and Hong Kong University Research Committee for the financial supports.

\section{REFERENCES}

Akyol DE, Bayhan GM. A review on evolution of production scheduling with neural networks. Computers \& Industrial Engineering 2007; 53(1); 95-122.

Banerjee A, Banerjee S. Coordinated, orderless inventory replenishment for a single supplier and multiple buyers through electronic data interchange. International Journal of Technology Management 1992; 7; 328-336.

Buzzell RD, Ortmeyer G. Channel Partnerships Streamline Distribution. Sloan Management Review 1995; 36(3); 85-96.

Cachon GP, Zipkin PH. Competitive and cooperative inventory policies in a two-stage supply chain. Management Science 1999; 45(7); 936-953. 
Cai GG, Zhang ZG, Zhang M. Game theoretical perspectives on dual-channel supply chain competition with price discounts and pricing schemes International Journal of Production Economics 2009; 117(1); 80-96.

Caldentey R, Wein L. Analysis of a decentralized production-inventory system. Manufacturing \& Service Operations Management 2003 5; 1-17.

Dumrongsiri A, Fan M, Jain A, Moinzadeh K. A supply chain model with direct and retail channels. European Journal of Operational Research 2008; 187(3); 691-718.

Graves SC, Willems S 2003. Supply Chain Design: Safety Stock Placement and Supply Chain Configuration. In: A. G. De Kok and S. C. Graves (Eds). Chapter 3 in Handbook in Operations Research and Management Science, Vol. 11. Amsterdam: Elsevier; 2003. p.95 -132 .

Huang GQ, Zhang XY, Liang L. Towards integrated optimal configuration of platform products, manufacturing processes, and supply chains. Journal of Operations Management $2005 ; 23(3-4) ; 267-290$.

Huang ZM, Li SX. Co-op advertising models in manufacturer-retailer supply chains: A game theory approach. European Journal of Operational Research 2001; 135(3); 527-544.

Kohli R, Sukumar R. Heuristics for product-line design using conjoint analysis. Management Science $1990 ; 36 ; 1464-1478$.

Liu BD. Stackelberg-Nash equilibrium for multilevel programming with multiple followers using genetic algorithms. Computers \& Mathematics with Applications 1998; 36(7); 79-89.

Michalewicz Z. Genetic Algorithms + Data Structures = Evolution Programs (2 ed.). New York: Springer-Verlag; 1996.

Onwubolu GC, Muting M. Optimizing the multiple constrained resources product mix problem using genetic algorithms. International Journal of Production Research 2001; 39(9); 1897-1910.

Press WH, Teukolsky SA, Vetterling WT, Flannery BP. Numerical Recipes: The Art of Scientific Computing (3 ed.): Cambridge University Press; 2007.

Raman N, Chhajed D. Simultaneous determination of product attributes and prices, and production processes in product-line design. Journal of Operations Management 1995; 12(3-4); 187-204.

Samuelson P. Foundations of economic analysis. Cam-bridge, Massachusetts: Harvard University Press; 1947.

Simchi-Livi D, Kaminsky P, Simchi-Livi E. Designing and Managing the Supply ChainConcepts, Strategies and Case Studies (3 ed.). New York: McGraw-Hill; 2008. 
Solnon C, Cung VD, Nguyen A, Artigues C. The car sequencing problem: Overview of stateof-the-art methods and industrial case-study of the ROADEF'2005 challenge problem. European Journal of Operational Research 2008; 191(3); 912-927.

Thonemann UW, Bradley JR. The effect of product variety on supply-chain performance. European Journal of Operational Research 2002; 143(3); 548-569.

Tyan J, Wee H-M. Vendor managed inventory: a survey of the Taiwanese grocery industry. Journal of Purchasing and Supply Management 2003; 9(1); 11-18.

Woo YY, Hsu SL, Wu SS. An integrated inventory model for a single vendor and multiple buyers with ordering cost reduction. International Journal of Production Economics 2001; $73(3) ; 203-215$.

Yang LL, Jones BF, Yang SH. A fuzzy multi-objective programming for optimization of fire station locations through genetic algorithms. European Journal of Operational Research 2007; 181(2); 903-915.

Yano C, Dobson G 1998. Profit-optimizing product line design, selection and pricing with manufacturing cost consideration. In: T. H. Ho and C. S. Tang (Eds). Product Varity Management: Research Advances: Kluwer Academic Publisher; 1998.

$\mathrm{Yu}$ Y, Chu F, Chen H. A Stackelberg game and its improvement in a VMI system with a manufacturing vendor. European Journal of Operational Research 2009a; 192(3); 929-948.

Yu Y, Huang GQ, Liang L. Stackelberg game theory model for optimizing advertising, pricing and inventory policies in vendor managed inventory (VMI) supply chains. Computers \& Industrial Engineering 2009b; accepted (link: http://dx.doi.org/10.1016/j.cie.2008.12.003).

Yue J, Austin J, Wang M-C, Huang Z. Coordination of cooperative advertising in a two-level supply chain when manufacturer offers discount. European Journal of Operational Research 2006; 168(1); 65-85.

Zhang T, Liang L, Yu Y, Yu Y. An integrated vendor-managed inventory model for a twoechelon system with order cost reduction. International Journal of Production Economics 2007; 109(1-2); 241-253. 


\section{APPENDIX A: INPUT PARAMETERS}

Table 6 Parameter values related to demand functions

(a) The value of $v_{m g x y}$

\begin{tabular}{|c|c|c|c|c|}
\hline \multicolumn{5}{|l|}{$v_{l 1 x v}$} \\
\hline$x \mid y$ & 1 & 2 & 3 & 4 \\
\hline 1 & 6.3 & -2.1 & -1.5 & -0.6 \\
\hline 2 & -1.9 & -1.6 & -1 & 0 \\
\hline 3 & -1.2 & 0 & 0 & -0.5 \\
\hline \multicolumn{5}{|l|}{$v_{12 x y}$} \\
\hline$x \mid y$ & 1 & 2 & 3 & 4 \\
\hline 1 & -1.6 & 6.6 & -1.6 & -1 \\
\hline 2 & -1 & -1.6 & -1 & 0 \\
\hline 3 & -1 & 0 & 0 & -1 \\
\hline \multicolumn{5}{|l|}{$v_{13 x v}$} \\
\hline$x \mid y$ & 1 & 2 & 3 & 4 \\
\hline 1 & -1.6 & -1.6 & 6.3 & -1.6 \\
\hline 2 & -1 & -1 & -1.6 & 0 \\
\hline 3 & -0.6 & 0 & 0 & -1 \\
\hline \multicolumn{5}{|l|}{$v_{14 x v}$} \\
\hline$x \mid y$ & 1 & 2 & 3 & 4 \\
\hline 1 & -1.2 & -1.5 & -1.9 & 7.2 \\
\hline 2 & -0.6 & -1 & -1.1 & 0 \\
\hline 3 & -0.6 & 0 & 0 & -1.5 \\
\hline \multicolumn{5}{|l|}{$v_{21 x y}$} \\
\hline$x \backslash y$ & 1 & 2 & 3 & 4 \\
\hline 1 & -2.6 & -1.6 & -1 & -0.6 \\
\hline 2 & 6.1 & -1.9 & -1.3 & 0 \\
\hline 3 & -1 & 0 & 0 & -0.7 \\
\hline \multicolumn{5}{|l|}{$v_{22 x v}$} \\
\hline$x \mid y$ & 1 & 2 & 3 & 4 \\
\hline 1 & -1 & -1.6 & -1 & -0.6 \\
\hline 2 & -1.6 & -6.3 & -1.6 & 0 \\
\hline 3 & -0.6 & 0 & 0 & -0.6 \\
\hline \multicolumn{5}{|l|}{$v_{23 x y}$} \\
\hline$x \backslash y$ & 1 & 2 & 3 & 4 \\
\hline 1 & -1 & -1.6 & -1 & -0.6 \\
\hline 2 & -1.6 & -6.3 & -1.6 & 0 \\
\hline 3 & -0.6 & 0 & 0 & -0.6 \\
\hline \multicolumn{5}{|l|}{$v_{31 x v}$} \\
\hline$x \mid y$ & 1 & 2 & 3 & 4 \\
\hline 1 & -1.6 & -1.2 & -1 & -0.9 \\
\hline 2 & -1.2 & -1 & -0.7 & 0 \\
\hline 3 & 8.3 & 0 & 0 & -1.5 \\
\hline \multicolumn{5}{|l|}{$v_{34 x v}$} \\
\hline$x \mid y$ & 1 & 2 & 3 & 4 \\
\hline 1 & -0.7 & -0.8 & -1 & -1.5 \\
\hline 2 & -0.5 & -0.6 & -1 & 0 \\
\hline 3 & -1 & 0 & 0 & 7.2 \\
\hline
\end{tabular}

Note: $v_{24 x y}, v_{32 x y}, v_{33 x y}$ are all zero. (b) The value of $e a_{m g x y}$

\begin{tabular}{|c|c|c|c|c|}
\hline$x \mid y$ & 1 & 2 & 3 & 4 \\
\hline 1 & 0.39 & 0.24 & 0.22 & 0.2 \\
\hline 2 & 0.2 & 0.16 & 0.17 & 0 \\
\hline 3 & 0.2 & 0 & 0 & 0.16 \\
\hline \multicolumn{5}{|l|}{$e a_{12 x v}$} \\
\hline$x \mid y$ & 1 & 2 & 3 & 4 \\
\hline 1 & 0.23 & 0.46 & 0.22 & 0.18 \\
\hline 2 & 0.16 & 0.2 & 0.16 & 0 \\
\hline 3 & 0.16 & 0 & 0 & 0.16 \\
\hline \multicolumn{5}{|l|}{$e a_{13 x y}$} \\
\hline$x \mid y$ & 1 & 2 & 3 & 4 \\
\hline 1 & 0.2 & 0.2 & 0.37 & 0.2 \\
\hline 2 & 0.18 & 0.18 & 0.2 & 0 \\
\hline 3 & 0.18 & 0 & 0 & 0.18 \\
\hline \multicolumn{5}{|l|}{$e a_{14 x y}$} \\
\hline$x \mid y$ & 1 & 2 & 3 & 4 \\
\hline 1 & 0.19 & 0.2 & 0.23 & 0.42 \\
\hline 2 & 0.2 & 0.16 & 0.17 & 0 \\
\hline 3 & 0.6 & 0 & 0 & 0.22 \\
\hline \multicolumn{5}{|l|}{$e a_{21 x y}$} \\
\hline$x \mid y$ & 1 & 2 & 3 & 4 \\
\hline 1 & 0.36 & 0.3 & 0.29 & 0.18 \\
\hline 2 & 0.4 & 0.33 & 0.3 & 0 \\
\hline 3 & 0.2 & 0 & 0 & 0.16 \\
\hline \multicolumn{5}{|l|}{$e a_{22 x y}$} \\
\hline$x \mid y$ & 1 & 2 & 3 & 4 \\
\hline 1 & 0.34 & 0.36 & 0.3 & 0.24 \\
\hline 2 & 0.4 & 0.41 & 0.32 & 0 \\
\hline 3 & 0.16 & 0 & 0 & 0.16 \\
\hline \multicolumn{5}{|l|}{$e a_{23 x y}$} \\
\hline$x \mid y$ & 1 & 2 & 3 & 4 \\
\hline 1 & 0.24 & 0.32 & 0.29 & 0.28 \\
\hline 2 & 0.32 & 0.34 & 0.37 & 0 \\
\hline 3 & 0.16 & 0 & 0 & 0.2 \\
\hline \multicolumn{5}{|l|}{$e a_{31 x y}$} \\
\hline$x \mid y$ & 1 & 2 & 3 & 4 \\
\hline 1 & 0.36 & 0.31 & 0.3 & 0.26 \\
\hline 2 & 0.2 & 0.16 & 0.14 & 0 \\
\hline 3 & 0.4 & 0 & 0 & 0.29 \\
\hline \multicolumn{5}{|l|}{$e a_{34 x y}$} \\
\hline$x \mid y$ & 1 & 2 & 3 & 4 \\
\hline 1 & 0.2 & 0.32 & 0.38 & 0.42 \\
\hline 2 & 0.13 & 0.18 & 0.24 & 0 \\
\hline 3 & 0.2 & 0 & 0 & 0.43 \\
\hline
\end{tabular}

Note. $e a_{24 x y}, e a_{32 x y}, e a_{33 x y}$ are all zero 
(c) The value of $\beta_{m g x y}$

\begin{tabular}{|c|c|c|c|c|}
\hline \multicolumn{5}{|l|}{$1 \times v$} \\
\hline$x \mid y$ & 1 & 2 & 3 & 4 \\
\hline 1 & $\begin{array}{l}-19 \\
\end{array}$ & 2.2 & 2.1 & 1.2 \\
\hline 2 & 2.5 & 1.6 & 1.2 & 0 \\
\hline 3 & 2.1 & 0 & 0 & 0.8 \\
\hline \multicolumn{5}{|l|}{$\beta_{12 x v}$} \\
\hline$x \mid y$ & 1 & 2 & 3 & 4 \\
\hline 1 & 1.8 & -25 & 1.9 & 1.5 \\
\hline 2 & 0.9 & 2.2 & 1.1 & 0 \\
\hline 3 & 1.2 & 0 & 0 & 0.7 \\
\hline \multicolumn{5}{|l|}{$\beta_{13 x y}$} \\
\hline$x \mid y$ & 1 & 2 & 3 & 4 \\
\hline 1 & 1.5 & 1.9 & -22 & 2 \\
\hline 2 & 1 & 1 & 21 & 0 \\
\hline 3 & 1.1 & 0 & 0 & 1.6 \\
\hline \multicolumn{5}{|l|}{$\beta_{14 x v}$} \\
\hline$x \backslash y$ & 1 & 2 & 3 & 4 \\
\hline 1 & 1.3 & 18 & 2.5 & -26 \\
\hline 2 & 0.7 & 1 & 18 & 0 \\
\hline 3 & 0.6 & 0 & 0 & 2.1 \\
\hline \multicolumn{5}{|l|}{$\bar{\beta}_{21 x y}$} \\
\hline$x \backslash y$ & 1 & 2 & 3 & 4 \\
\hline 1 & 2.4 & 1.6 & 1 & 0.7 \\
\hline 2 & -19 & 1.9 & 1.3 & 0 \\
\hline 3 & 1 & 0 & 0 & 0.6 \\
\hline
\end{tabular}

(g): The value of $e A_{m g y}$

\begin{tabular}{l|llll}
\hline$e A_{m g y} \mid y$ & 1 & 2 & 3 & 4 \\
\hline$e A_{11 y}$ & 0.35 & 0.26 & 0.2 & 0.18 \\
$e A_{12 y}$ & 0.21 & 0.36 & 0.21 & 0.15 \\
$e A_{13 y}$ & 0.17 & 0.22 & 0.34 & 0.21 \\
$e A_{14 y}$ & 0.1 & 0.19 & 0.21 & 0.36 \\
$e A_{21 y}$ & 0.32 & 0.25 & 0.12 & 0 \\
$e A_{22 y}$ & 0.2 & 0.33 & 0.2 & 0 \\
$e A_{23 y}$ & 0.17 & 0.23 & 0.35 & 0 \\
$e A_{24 y}$ & 0 & 0 & 0 & 0 \\
$e A_{31 y}$ & 0.32 & 0 & 0 & 0.2 \\
$e A_{32 y}$ & 0 & 0 & 0 & 0 \\
$e A_{33 y}$ & 0 & 0 & 0 & 0.36 \\
$e A_{34 v}$ & 0.23 & 0 & 0 & \\
\hline
\end{tabular}

(h):The value of $u_{m g y}, \mathrm{y}, \mathrm{g} \in \mathrm{G}, \mathrm{m} \in M(g)$

\begin{tabular}{l|llll}
\hline$u_{m g y} \mid y$ & 1 & 2 & 3 & 4 \\
\hline$u_{11 y}$ & 12 & -1.8 & -1.5 & -1.1 \\
$u_{12 y}$ & -1.7 & 18 & -1.2 & -0.9 \\
$u_{13 y}$ & -1 & -1.9 & 11 & -1.9 \\
$u_{14 y}$ & -0.9 & -1.1 & -2.1 & 16 \\
$u_{21 y}$ & 12 & -2.2 & -1 & 0 \\
$u_{22 y}$ & -1.7 & 18 & -1.8 & 0 \\
$u_{23 y}$ & -1.7 & -1.9 & 11 & 0 \\
$u_{24 y}$ & 0 & 0 & 0 & 0 \\
$u_{31 y}$ & 11 & 0 & 0 & -1 \\
$u_{32 y}$ & 0 & 0 & 0 & 0 \\
$u_{33 y}$ & 0 & 0 & 0 & 0 \\
$u_{34 y}$ & -1.3 & 0 & 0 & 18 \\
\hline
\end{tabular}

\begin{tabular}{|c|c|c|c|c|}
\hline$x \mid y$ & 1 & 2 & 3 & 4 \\
\hline 1 & 1 & 2.1 & 1.2 & 0.8 \\
\hline 2 & 1.6 & 1.8 & 1.6 & 0 \\
\hline 3 & 1.1 & 0 & 0 & 0.5 \\
\hline \multicolumn{5}{|l|}{$\beta_{23 x v}$} \\
\hline$x \backslash y$ & 1 & 2 & 3 & 4 \\
\hline 1 & 0.8 & 1.1 & 1.8 & 1 \\
\hline 2 & 15 & 25 & -25 & 0 \\
\hline 3 & 0.6 & 0 & 0 & 0.7 \\
\hline \multicolumn{5}{|l|}{$\underline{\beta}_{31 x y}$} \\
\hline$x \mid y$ & 1 & 2 & 3 & 4 \\
\hline 1 & 2.3 & 1.8 & 1.1 & 0.8 \\
\hline 2 & 1.1 & 1 & 0.7 & 0 \\
\hline 3 & -18 & 0 & 0 & 1.9 \\
\hline \multicolumn{5}{|l|}{$\beta_{34 x v}$} \\
\hline$x \mid y$ & 1 & 2 & 3 & 4 \\
\hline 1 & 1 & 1.5 & 2.1 & 2.2 \\
\hline 2 & 0.5 & 0.6 & 0.7 & 0 \\
\hline 3 & 1.1 & 0 & 0 & -23 \\
\hline \multicolumn{5}{|c|}{$\begin{array}{l}\text { The elements of } \beta_{24 x y}, \beta_{32 x y}, \beta_{33 x y} \text { are all zero. } \\
\text { (d): } K_{m g}\end{array}$} \\
\hline$m \backslash g$ & 1 & 2 & 3 & 4 \\
\hline 1 & 700 & 800 & 800 & 900 \\
\hline 2 & 700 & 900 & 700 & 0 \\
\hline 3 & 900 & 0 & 0 & 800 \\
\hline
\end{tabular}

(e): $e P_{m g x y}=1, x, m \in M ; g \in G, y \notin G(x)$. 
Table 7 Values of some other parameters

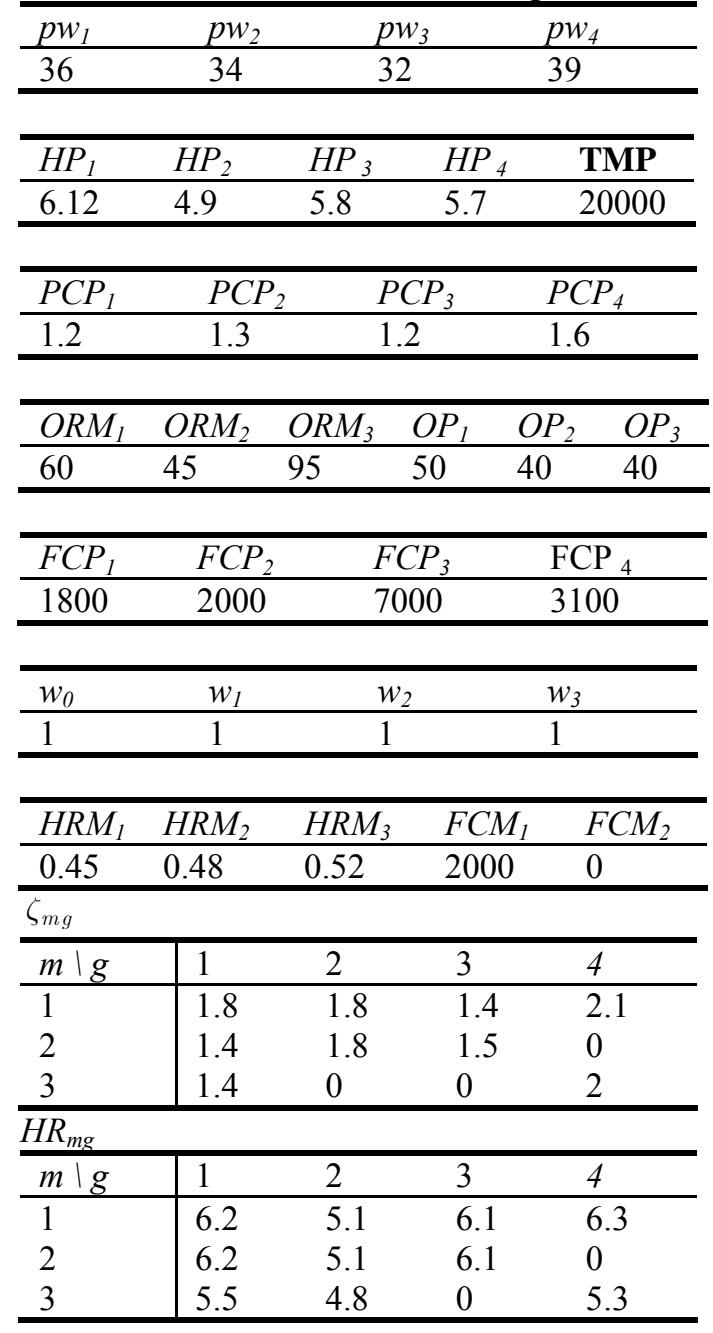

\begin{tabular}{|c|c|c|c|c|}
\hline \multicolumn{5}{|l|}{$H R_{m g}$} \\
\hline$m \backslash g$ & 1 & 2 & 3 & 4 \\
\hline 1 & 6.2 & 5.1 & 6.1 & 6.3 \\
\hline 2 & 6.2 & 5.1 & 6.1 & 0 \\
\hline 3 & 5.5 & 4.8 & 0 & 5.3 \\
\hline \multicolumn{5}{|l|}{$P C R_{s l}$} \\
\hline$s \backslash l$ & 1 & 2 & & 3 \\
\hline 1 & 0.9 & 1.1 & & 1.4 \\
\hline 2 & 1 & $+\infty$ & & 1.2 \\
\hline 3 & 1.1 & 1 & & $+\infty$ \\
\hline \multicolumn{5}{|l|}{$F C A_{j k}$} \\
\hline$j \backslash k$ & 1 & 2 & & 3 \\
\hline 1 & 1700 & 1900 & & 4600 \\
\hline 2 & 0 & 0 & & 0 \\
\hline \multicolumn{5}{|l|}{$T \bar{P}_{m g}$} \\
\hline$m \backslash g$ & 1 & 2 & 3 & 4 \\
\hline 1 & 1.4 & 1.7 & 1.4 & 1.4 \\
\hline 2 & 1.5 & 2.5 & 1.8 & $\infty$ \\
\hline 3 & 1.4 & $\infty$ & $\infty$ & 1.6 \\
\hline \multicolumn{5}{|l|}{$P C A_{j k}$} \\
\hline$j \backslash k$ & 1 & 2 & & 3 \\
\hline 1 & 0.9 & 1.1 & & 1.2 \\
\hline 2 & 0 & 0 & & 0 \\
\hline
\end{tabular}

$T A=13350$, the values of other parameters not given are not included in our calculations. 


\section{Publications in the Report Series Research ${ }^{*}$ in Management}

\section{ERIM Research Program: "Business Processes, Logistics and Information Systems"}

2009

How to Normalize Co-Occurrence Data? An Analysis of Some Well-Known Similarity Measures

Nees Jan van Eck and Ludo Waltman

ERS-2009-001-LIS

http://hdl.handle.net/1765/14528

Spare Parts Logistics and Installed Base Information

Muhammad N. Jalil, Rob A. Zuidwijk, Moritz Fleischmann, and Jo A.E.E. van Nunen

ERS-2009-002-LIS

http://hdl.handle.net/1765/14529

Open Location Management in Automated Warehousing Systems

Yugang YU and René B.M. de Koster

ERS-2009-004-LIS

http://hdl.handle.net/1765/14615

VOSviewer: A Computer Program for Bibliometric Mapping

Nees Jan van Eck and Ludo Waltman

ERS-2009-005-LIS

http://hdl.handle.net/1765/14841

Nash Game Model for Optimizing Market Strategies, Configuration of Platform Products in a Vendor Managed Inventory (VMI) Supply Chain for a Product Family

Yugang Yu and George Q. Huang

http://hdl.handle.net/1765/15029

ERS-2009-009-LIS

* A complete overview of the ERIM Report Series Research in Management: https://ep.eur.nl/handle/1765/1

ERIM Research Programs:

LIS Business Processes, Logistics and Information Systems

ORG Organizing for Performance

MKT Marketing

F\&A Finance and Accounting

STR Strategy and Entrepreneurship 